\title{
A REVIEW ON PERFORMANCE ENHANCEMENT OF SOLAR AIR HEATER
}

\section{RAVISH KUMAR SRIVASTAVA \& AJEET KUMAR RAI}

Department of Mechanical Engineering, SIET, SHUATS, Allahabad, Uttar Pradesh, India

ABSTRACT

In this paper, a review of the available literature on $\mathrm{SAH}$, for the performance improvement is presented; the review is made to allow a discussion based on fins, baffles \& obstacles, proposed by various researchers. Considering the parameters, which is enhancing the performance of SAH. The review covers the overview of different, description of absorber plate geometry, \& parameters which affecting the performance of SAH are covered. Performance \& its improvement by various geometrical changes, on the absorber plate are paying attention.

KEYWORDS: Solar Collectors, Obstacles, Fins, Heat Loss, Baffles, Thermal Efficiency, Exergy, etc.

Received: Jul 19, 2017; Accepted: Aug 09, 2017; Published: Oct 03, 2017; Paper Id.: IJMPERDOCT201729

\section{INTRODUCTION}

The fast growth of population \& industrialization are the basic reasons behind increasing energy demand. Conventional energy sources are used to meet this demand. Developing countries are heavily dependent on fossil fuels, for their energy needs. This causes depletion of fossil fuel resources, and degradation of the environment. Use of renewable energy sources may be alternative to the fossil fuels, which also saves the environment. Therefore, there is a great need to explore the renewable energy sources, and to develop the renewable energy, based technologies to meet our energy demand in the present context. Solar energy is the one most abundant renewable energy source, and emits energy at a rate of $3.8 \times 10^{23} \mathrm{~kW}$ of which, approximately $1.8 \mathrm{x} 10^{14} \mathrm{~kW}$ is intercepted by the earth [1]. There are lots of review articles, already published in the area of air heaters. This review aims to merge the efforts of the researchers working on SAH, and find the pathways to present it by means of robust applications to use, and thus, to enhance the performance for consideration in the design and development. [2] The most important use of solar thermal technology \& its application is drying air, which is further utilized for space heating, especially in winter's \& for all drying processes, wherever applicable. [3] The easiest \& the most able way to make use of solar energy are, to transfer the thermal energy for drying applications, through the use of solar collectors. SAH's, because of simple design are cheap \& most commonly used [4]. The thermal performance ability of solar collectors, depends on- material \& shape \& layout of the collectors. The raise in performance improvement could be possible with these parameters. The modification helps to improve the heat transfer coefficient, in-between the absorber plate \& the air, which includes use of absorbers with corrugated \& matrix type, with packed bed, baffles \& fins etc. Their various configurations is disused in this literature.

\section{PERFORMANCE ENHANCEMENT}

There are lot's studies are taking place, for the improvements of SAH performance. They found that, to 
improve the performance of SAH, several ways \& methods may be exercised such as, providing fins or obstacles or baffles etc., on the absorber plate. Also, while providing \& improving the surface roughness has a grand effect, on the SAH performance.

\section{IMPACT OF USE OF FINS}

The main purpose of providing fins is, to enhance the area of heat transfer \& hence, escalating the efficiency of the heater. So that, impact of fin height, numbers \& arrangement on the concert is studied either practically or theoretically.

- Longitudinal Fins: The effect of the air mass flow rate on exit temperature, heat transfers via solar collector, \& the thermal efficiency is investigated, practically by Foued et al. [5]. Figure 1, depicts a schematic view of solar box with \& without fins. The impact of fin number, height \& fin arrangement is absent. Paisarn [6] have discussed the mathematical model, to predict the effects of height \& number of fins, on heat transfer behavior, the performance \& entropy generation of DPSAH, along with longitudinal fins. The outcome predicts that, efficiency increases, when increasing height \& number of fins, \& the entropy generation is inversely proportional to height \& number of fins.

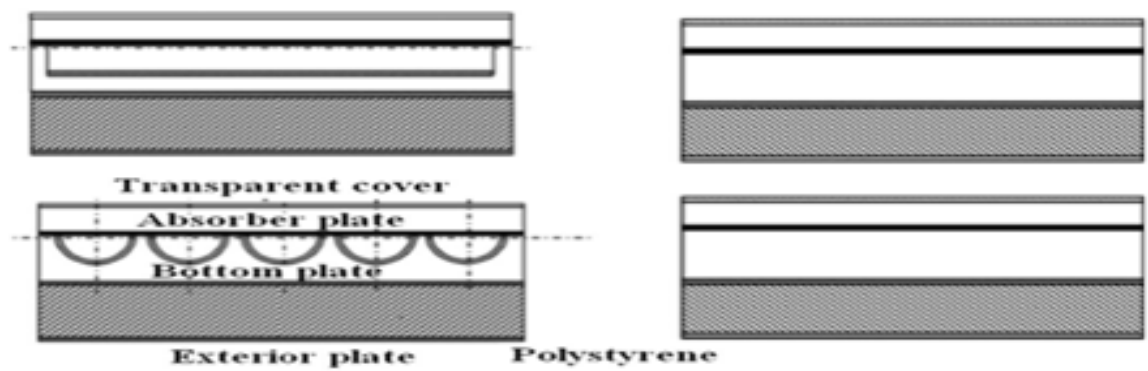

Figure 1: A Solar Box With \& Without Fins [5]

Omojaro and Aldabbagh [7], investigated practically the thermal excellence of a single \& double-pass SAH, along with fins attached \& uses steel wire mesh as absorber plate Figure 2. It is noticeable that, for the same flow rate, efficiency of double pass is higher than the single pass by $7-19.4 \%$. Higher efficiency obtained from double \& single pass SAH is $63.74 \%$ \& 59.62\%, correspondingly. Furthermore, the efficiency reduces with raising the height of the first pass of double pass SAH's. In results discovered that, use of steel wire mesh arrangement of layers in place of absorber plate, \& packing material helps to enhance the efficiency.

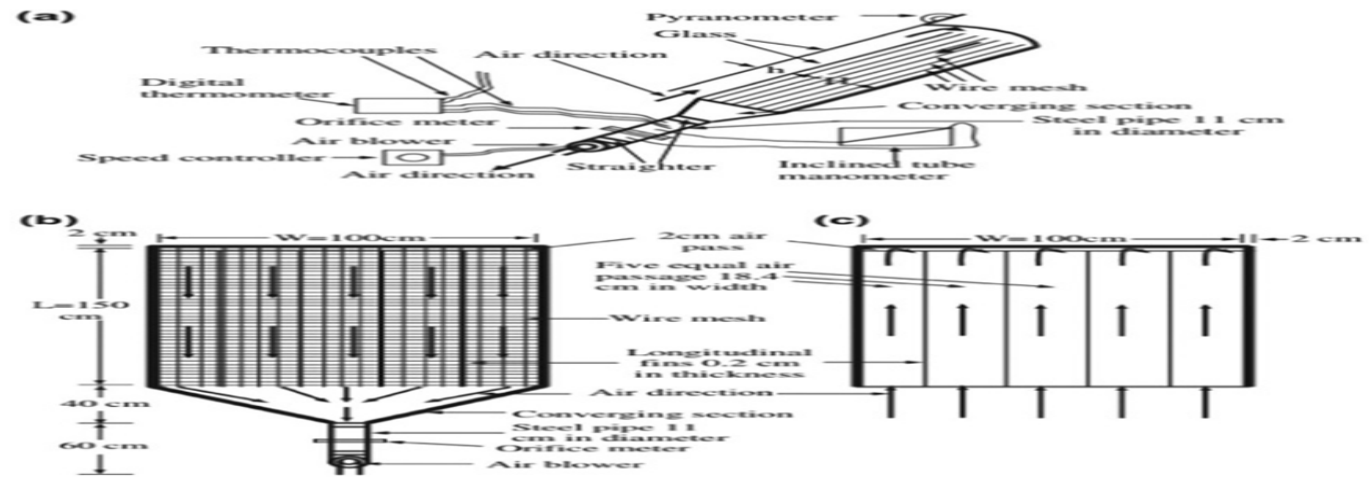

Figure 2: Single \& Double Pass SAH Showing, (a) Figure of the Practical Rig, (b) Lowers Pass Channel, (c) Upper Pass Channel [7] 
Yeh [8] have studied to the impact of internal recycle, on collector performance on the upward-type FPSAHs, with fins as shown in Figure 3. The results depict that, the raise in SAH efficiency, increased with rising reflux ratio, particularly for performing at the low mass flow of air, with high inlet air temperature. Furthermore, performance in the apparatus, operated with internal recycle overcomes that, in same size device performed by external recycle. The study excludes the consideration of the effect on the fin number's, height $\&$ fin arrangement.

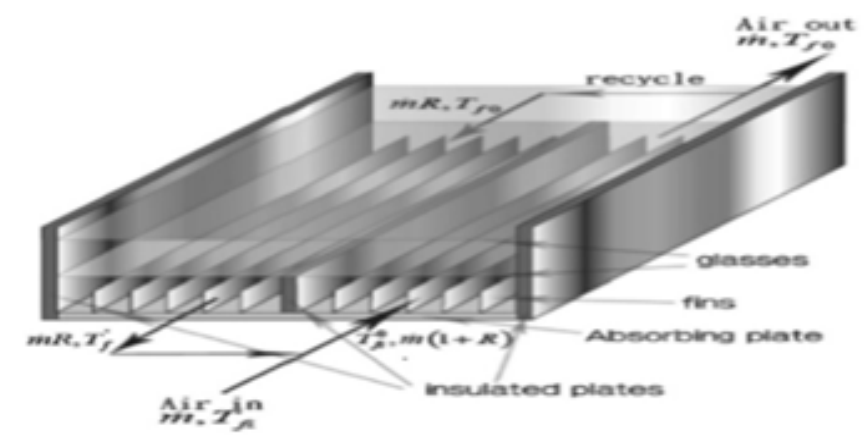

Figure 3: View of an Upward-Type Internally-Recycle Flat-Plate SAH with Fins [8]

Alta et al. [9], have made a comparison of 3 dissimilar types of SAHs, with the arrangement indicated in Figure 4. He has concluded that, thermal efficiency of the finned collector's is higher as compare to SAH, without fins for the reason that, the higher irreversibility occurs to the heater without fins. Also, temperature deviation increased, though utilizing more transparent glass cover \&fins. The increase in air flow rates led to enhance the energy efficiency of SAH, \& decreasing temperature difference of fluid at a stable tilt angle.
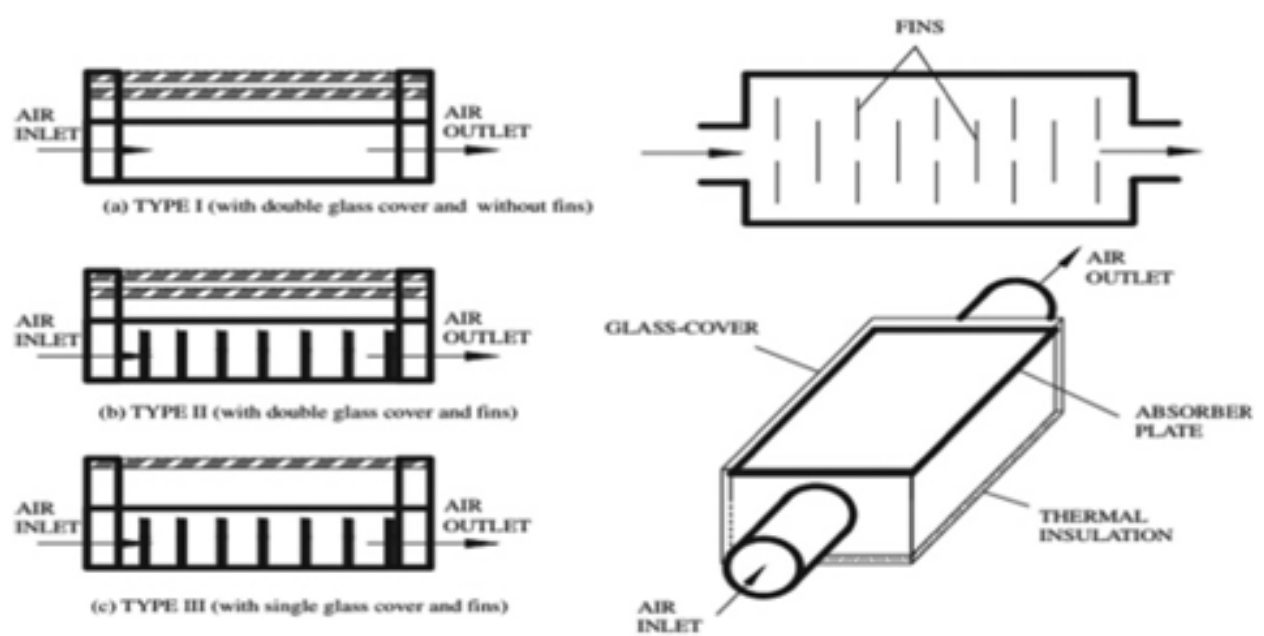

(e) TrPE III (with single glaws cover and fins)

Figure 4: Diagram of the Tested Heaters [9]

- With Baffles: Bayrak et al. [10], the test is fabricated to investigate theoretically \& experimentally the SAH, with baffle's are attached, if in a staggered style shown in Figure 5. The observation takes place at two dissimilar mass flow rates of $0.016 \mathrm{~kg} / \mathrm{s} \& 0.025 \mathrm{~kg} / \mathrm{s}$. The maximum SAH efficiency \& temperature rise of exit air, is obtained by heaters with a six mm thickness \& an air mass flow rate of $0.025 \mathrm{~kg} / \mathrm{s}$, while, the minimum values are noticed for the non-baffles SAHs \& a fluid mass flow rate of $0.016 \mathrm{~kg} / \mathrm{s}$. 
(a)
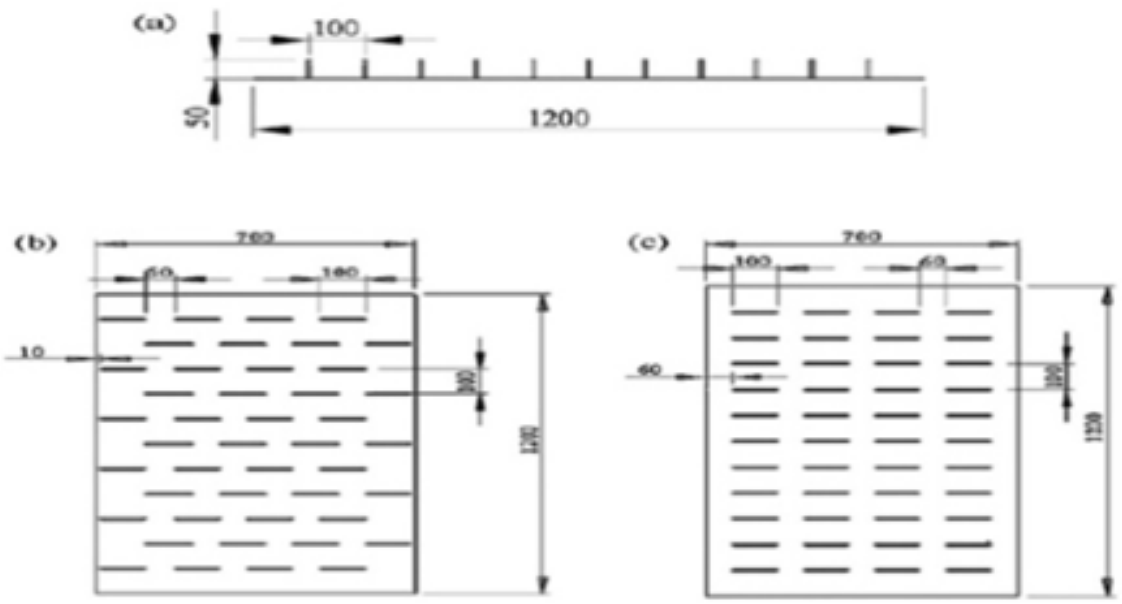

Figure 5: The Aluminum Foams (a) Side View of the Sequence \& Staggered Arrays,

(b) Top View of the Staggered Array, \& (c) Top View of the Sequence Array [10]

Ho et al. [11], investigated theoretically \& practically the working of a SAH, with double-pass \& as fins or baffles, with recycled as indicated in Figure 6. The practical results diverge by $1.5-23 \%$, then the theoretical predictions. The performance of SAHs of different designs is compared inbetween them. On the basis of both theoretical \& practical results, the collector efficiency of fine based double-pass, along with recycled design is higher, as compared to the other designs considering different reflux ratios \& mass flow rates. The optimized reflux ratio of the fined based double-pass design is around 0.5 , while considering both collector efficiency \& pumping power requirement.

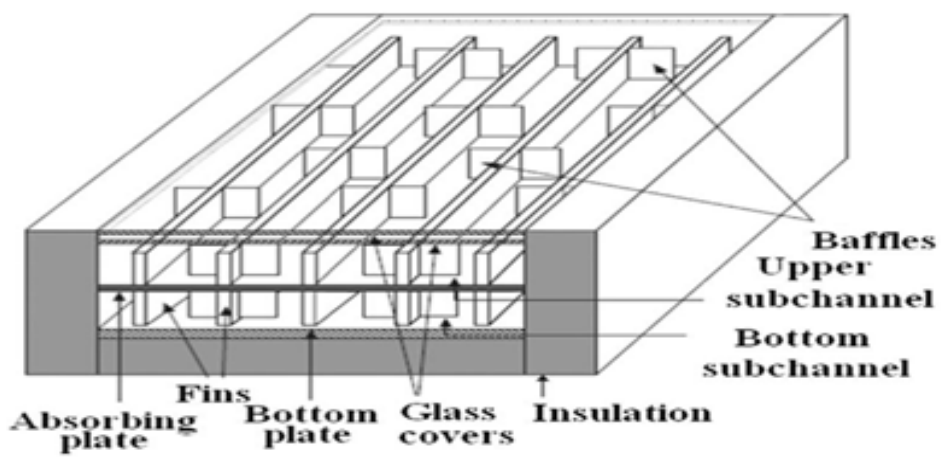

Figure 6: Fined Baffeled Double-Pass SAH [11]

Mohammad and Sabzpooshani [12], have studied the parametric effect of the fins, \& baffles of single pass SAH. The effect of mass flow rate \& solar radiation intensity are analyzed. As compared with simple air heater, the exit temperature, useful energy \& efficiency raised as a result of attaching fins \& baffles. While increasing the air flow rate in result, it reduces the exit temperature sharply. In adding up, fins \& baffles parameters have a slight impact on the exit temperature, when the mass flow rate enhanced over $0.03 \mathrm{~kg} / \mathrm{s}$. The results predict that, increasing the fin's width \& baffles and reducing the gap between them, led to improve the performance, but further, while increasing these parameters increases the required pump work \& hence, minimizing the enhancement. The baffle width is a critical parameter, at the high mass flow rates \& must be carefully selected for the reason that of higher pressure drops. Selecting optimizes parameters of fins \& baffles were found to be uncertain, in all mass flow rates, but can be analyzed for any mass flow rate. The higher solar intensity results higher exit temperature \& useful energy, but the efficiency reduced.

Ho et al. [13], investigated theoretically \& practically the performances of finned \& baffled DPSAH, with external 
recycle operation as shown in Figure 7. Using reprocess process with finned \& baffled heater is a good intend, for improving the performance \& efficiency of the heater, as baffles produce higher turbulence hence, increases heat-transfer area \& enhancing heat transfer coefficient. Improving the mass flow rate, \& recycle ratio improves the collector efficiency, but, it causes higher energy dissipation. As per the theoretical results, maximum percentage of collector efficiency enhancement is $126.30 \%$, in mass flow rate of $38.52 \mathrm{~kg} / \mathrm{h}$, recycle ratio of 2 \& solar intensity of $830 \mathrm{~W} / \mathrm{m}^{2}$. But, experimental results predict that, the maximum useful energy is $51.46 \mathrm{~W}$, at a mass flow rate of $38.52 \mathrm{~kg} / \mathrm{h}$, recycle ratio of $2 \&$ solar intensity of $830 \mathrm{~W} / \mathrm{m}^{2}$.

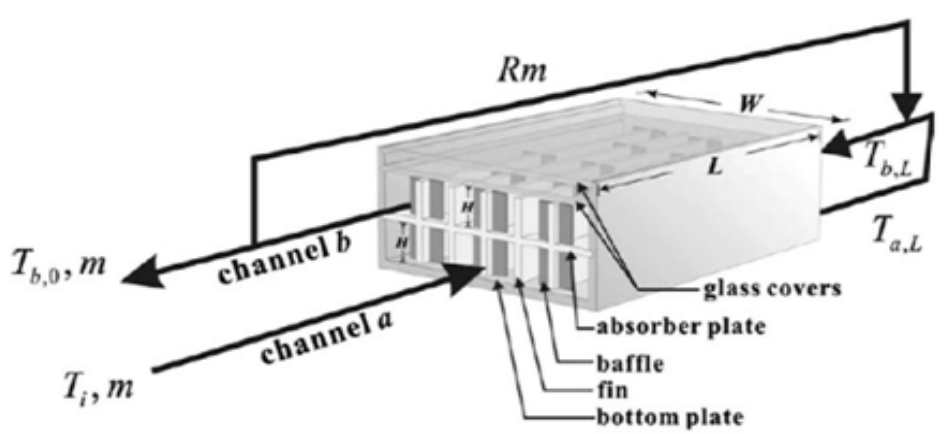

Figure 7: Bafflled SAH with Internal Fins Attached \& External Recycle [13]

- Corrugated fins: Karim \& Hawlader [14], have practiced \& theoretically studied finned \& v-corrugated SAHs, under similar working conditions. It is noticed that, v-corrugated collector is $5-11 \%$ \& $10-15$ extra efficient in a double pass \& single pass mode, correspondingly, compare with FPC. Also, the efficiency in all 3 collectors, improved with rising mass flow rate, \& saturated beyond a flow rate of $0.056 \mathrm{~kg} / \mathrm{m}^{2} \mathrm{~s}$. In double pass, the enhancement in efficiency was most significant in the FPC \& small in the v-groove collectors. Figure 8 , depicts the layout of collectors.

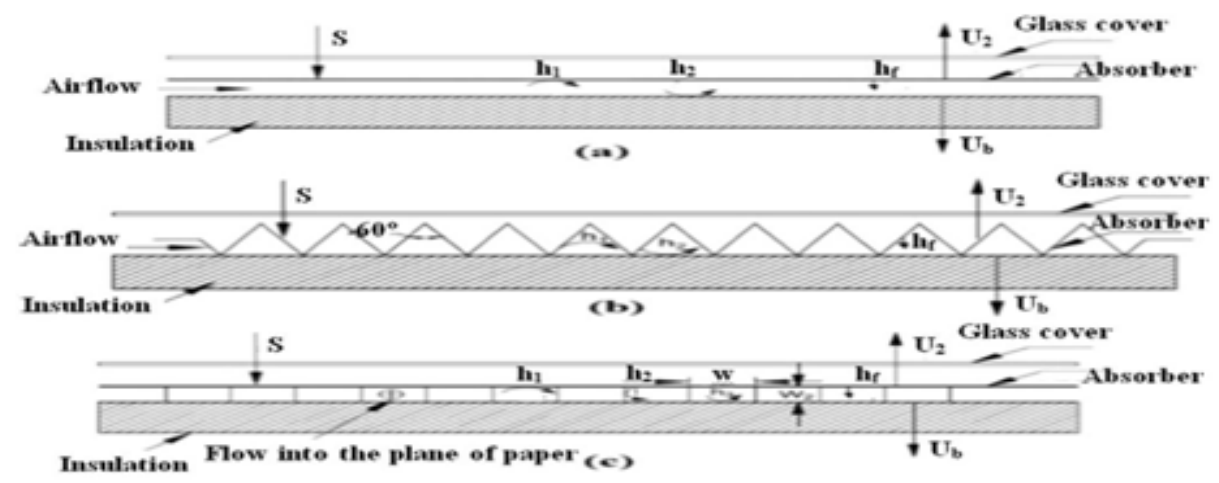

Figure 8: Layout of a FPSAC, b- V-Groove Air Collector \& c-Finned Collector [14]

El-Sebaii et al. [15], Analyzed practically \& theoretically impact of mass flow rate of air on pressure drop. The thermal efficiency of double pass v-corrugated \& finned plate SAHs, is investigated. It is observed that, double pass vcorrugated plate SAH is $9.3-11.9 \%$, more efficient as compared to double pass-finned plate.

Gao et al. [16], predicted analytically \& practically, thermal act of SAH made up of a wave type crossed position, absorbing plates as compared with FPSAH, flat absorbing-plate \& flat bottom-plate. The air flow way is prepared to improve the turbulence \& heat-transfer rate \& hence, raise the efficiencies of SAHs. 2 types of heaters are depicted in Figure 9. In type I heater, wavelike shape of absorbing plate am placed, along the flow direction, whereas bottom plate is at 
right angles to the flow direction \& vice-versa, for type II. The thermal performance of the type II heater is the uppermost one then type 1 . Under same configurations \& operating conditions, efficiencies of $58.9 \%, 60.3 \%$ \& $48.6 \%$ of type I, type II FPSAH, could achieve, in that order. Results shows, use of selected coatings on absorbing plates enhances performance.
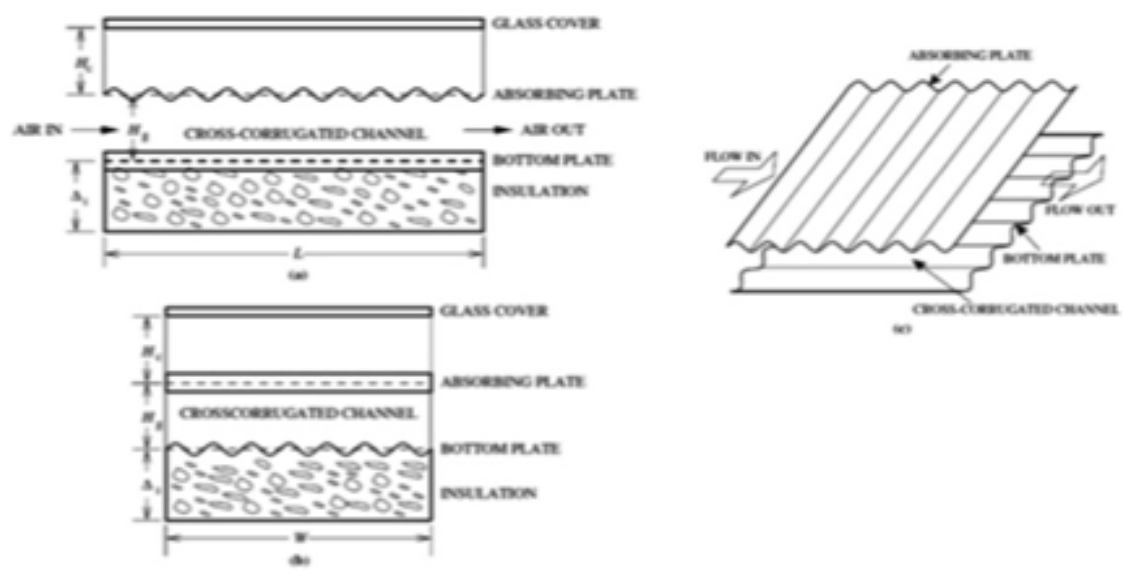

Figure 9: (a) C/S View at Right Angles to Flow Direction; (b) C/S View along Flow Direction; \& (c) Fig of Cross-Corrugated Absorbing Plate \& Bottom Plate [16]

\section{EFFECT'S OF ARTIFICIAL ROUGHNESS}

Artificial roughness is extensively introduced for the enrichment of forced convection heat transfer; it requires a turbulent flow on the heat transfer fade, so that, it is used to improve heat transfer \& hence, improving thermo hydraulic performance of SAH. As forced convection heat transfer requires energy coming from a fan \& or a blower, turbulence is taking place close to the heat transfer plane, to decrease the power requirement. It can be achieved, while maintaining the element height small, as compared to heater duct dimensions. To describe roughness, dimensionless geometrical parameter is used [17], as the relative roughness of pitch, \& height, \&Angle of attack, \& Aspect ratio \& the shape of roughness element.

Yadav \& Bhagoria [18], introduced a 2-D CFD model of SAH, along with an equal angle triangular sectioned rib roughness, on absorber plate, Figure 10. The analysis concerned about the effect of 3 parameters, on thermos-hydraulic performance of roughen heater: relative roughness pitch, \& roughness height\& Reynolds number (Re). The result gives the middling $\mathrm{Nu}$. Number has the trend to enhance with the increase of Re, in all the cases but, middling friction factor reduces. Whereas, the average Nusselt number \& average friction factor reduce, with increase in relative roughness of pitch at set value of the relative roughness height $\&$ increase of relative roughness height, to improve a set value of relative roughness pitch. It notices that, for height of relative roughness $0.042 \&$ pitches of relative roughness 7.14 , the highest number \& friction factor improvement notice at Re of 15,000 \& 3800, correspondingly. The great enhancement in Nu \& friction factor enhancement over the smooth duct is found as 3.072 times, \& 3.355 times, respectively. 


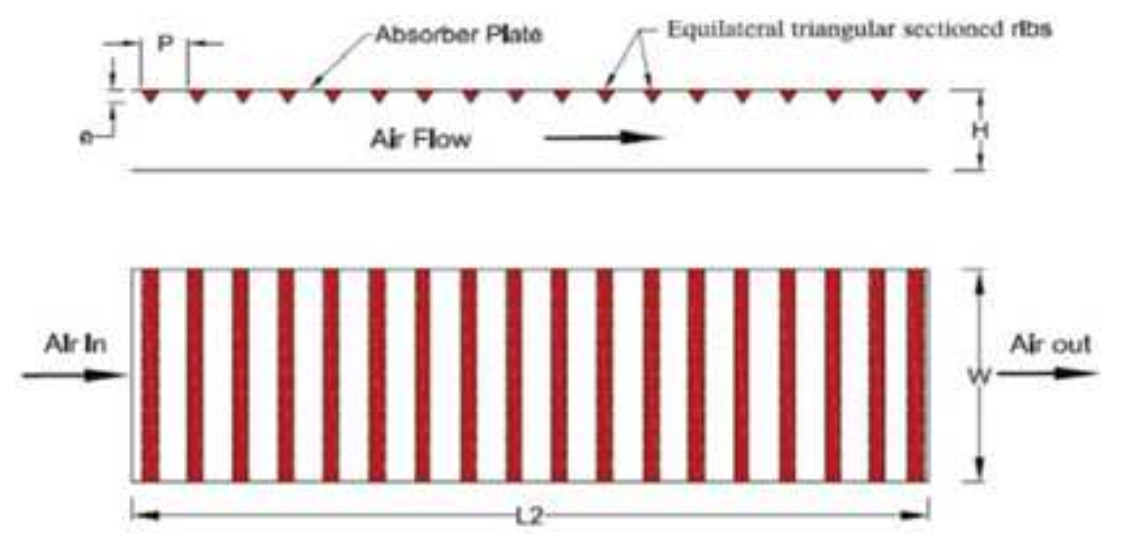

Figure 10: View of Roughened Absorber Plate [18]

Gupta \& Kaushik [19] performed an analysis in artificially roughened SAH, \& integrated with extended metal mesh, on the absorber plate compared with conventional heater. The study is exercised to evaluate performance in way of ratios of energy expansion, useful energy expansion \& exergy augmentation at different Reynolds numbers $(\mathrm{Re})$, \& roughness parameters on prolonged metal mesh unevenness geometry. The expansion ratio is improved, by using extended metal mesh type roughened geometries in the duct. The EXAR reduces with Re, \& may be less than unity \& may be negative when exergy of the pump work required, \& it becomes larger than the exergy of the heat energy collected in roughened heater, but it is greater than unity for the larger flow c area/s of the heater, along with low Re values $\&$ higher solar radiation intensity.

Peng et al. [20] analyzed the thermal efficiency of novel SAH of pin-fin incorporated absorber. The result predicts that, heat transfer coefficients for pin-fin array collectors \& flat-plate collector is performed, at an air flow rate of $19 \mathrm{~m}^{3} / \mathrm{h}$. The outcomes showed that, the heat transfer coefficient of pin-fins SAH is 3 times that of FPSAH. Also, the middling thermal efficiency reached $0.5 \%-0.74 \%$. Correlation equation is used for getting the highest thermal efficiency, as a function of dimensionless pin-fin span \& dimensionless pin-fin height. Also, correlation equation was exercised, to calculate heat transfer coefficient.

Momin et al. [21] made a survey on the V-shaped rib, to examine the effect of relative roughness \&height \&angle of attack. This study is confined for fixed relative roughness pitch \& height, about 10\&0.034, along with a Reynolds number of range 2500 to 18000 . The display of ribs is illustrated in Figure 11. The results predict the rate of enhancement in friction coefficient was higher, than that of the rate of increase of the Nusselt number, due to raise of Reynolds number. Use of V-shaped ribs achieves an improvement in Nusselt number, from 1.14 \& 2.30 times over inclined ribs \& smooth plate.

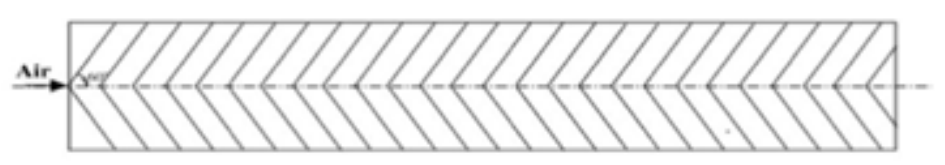

Figure 11: Type \& Orientation of the Roughness Element [21]

The outcome of transverse \& inclined, V- discrete, \& continuous types of heat transfer $\&$ friction factor, in rectangular duct is analyzed by Karwa [22]. All these types are tested at slope $60^{\circ}$. V- Patterns are studied, for up \& down streams. For the V-up continuous \& V-down continuous, V-up distinct \& V-down distinct, the improvement in the St 
number is $137 \%, 147 \%, 134 \%$ \& $142 \%$, correspondingly, over smooth duct \& friction factor is up to $3.92,3.65,2.47$ $\& 2.58$, accordingly.

Agarwal et al. [23], Inclined split \& rib arrangement in rectangular duct of a SAH is exercised, to analyze the impact of gap - width ratio (g/e) \& gap - position ratio (d/W). The performance is enhanced, because of gaps in rib.

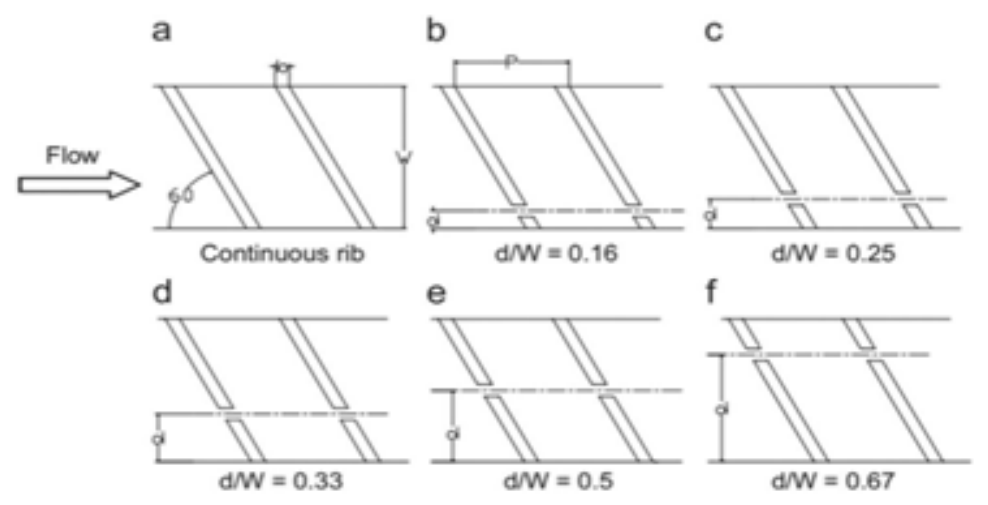

Figure 12: Variation of Gap Position Variation in an Inclined Rib Arrangement [23]

In a series of 1.48-2.59 times of flat duct friction factor, enlarged in the range of 2.26-2.9 times, that of smooth duct. A relative gap position of $0.25 \&$ relative gap width of 1.0, gives the greatest values of Nusselt number, friction factor $\&$ thermo-hydraulic performance. Figure 12, shows the deviation of gap position in an inclined rib position.

Jaurker et al. [24], investigated comparative roughness pitch \& height, \& groove position on both heat transfer coefficient \& friction factor of rib-grooved artificial roughness, as shown in Figure 13. Comparative roughness on the pitch of $6 \mathrm{~mm}$ achieved the optimum heat transfer.

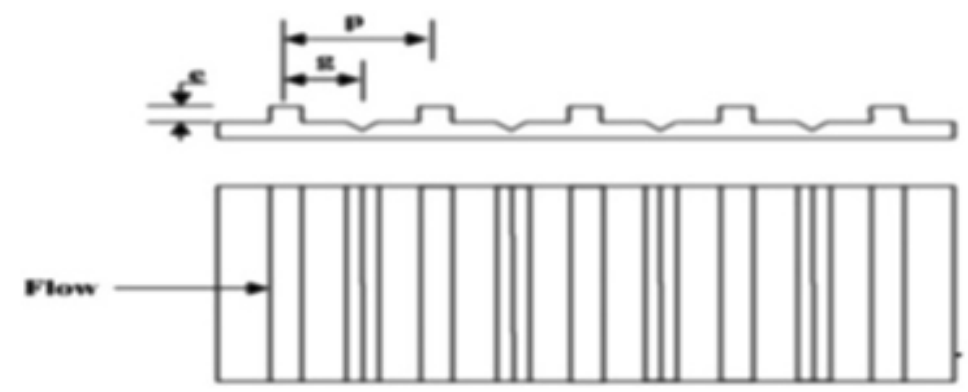

Figure 13: Rib Grooved Roughness [24]

The impact of inverted U-shaped turbulators, on the absorber plate surface on SAH duct, heat transfer coefficient \& friction factor is analyzed by Bopche \& Tandale [25]. As Compared to ribs, \& the inverted U-shaped turbulators improved significantly the heat transfer at low Reynolds number $(\operatorname{Re}<5000)$. The greatest values of Nusselt number \& friction factor is $2.388 \& 2.50$, respectively, $\mathrm{Re}=3800$ it compares with level duct these values are $2.82 \& 3.72$. Higher heat transfer improvement at a reasonable friction penalty occurred at a generation of turbulence, in viscous sub-layer region of the boundary layer.

Lanjewar et al. [26], have experimentally checked the impact of W-shape rib irregularity on heat transfer, friction uniqueness \& thermos-hydraulic act. The rough surface has a comparative roughness on pitch of about $10, \&$ height 0.018 , duct aspect ratio 8 , the rib height $0.8 \mathrm{~mm} \&$ angle of attack of range $30-60^{\circ}$. As Compared with smooth duct, The Nusselt number enrichment is $32-92 \%, \& 31-81 \%$, and $9-56 \%$ for the $60^{\circ}, 45^{\circ} \& 30^{\circ}$, accordingly. The optimum attack angle is 
suggested as $60^{\circ}$

\section{CONCLUSIONS}

SAH is a simple device; it captures solar energy \& producing hot air. The clean energy heating technology used to process the heat generated, for all the drying purposes. It produces heat at zero cost, \& using the sun as energy source \& it is freely accessible. It requires the least amount of repairs such as cleaning of collectors, etc. [27] Using fins increase area for heat transfer \& hence, gains in improvement. Efficiency could reach $60 \%$ in DPSAH. Lowering the mass flow rate leads to reduce the thermal efficiency of $\mathrm{SAH}, \&$ also extreme rising in mass flow rate gives the same effect, because of leakage. Attaching baffles \& also recycle method gets better efficiency of the heater. Hence, designer has to select height \& width of baffles cautiously. The v-corrugated SAH is observed as most proficient SAH, then FPSAH. Performance investigation predicts that, v-corrugated SAH is $5-10 \% \& 10-15 \%$, additional efficient in double pass \& single pass types, accordingly against FPSAH. Choosing best configuration of fins \& baffles is found to be firm, in all the mass flow rates \& also evaluated for every mass flow rate. The higher solar intensity results higher exit temperature \& useful energy, hence, efficiency decreased. Artificial irregularity enhances, both heat transfer\& thermo hydraulic performance of SAH. Using artificial roughness, the allmost efficiency reaches approx... $62 \%$.

\section{REFERENCES}

1. Srivastava Ravish and Rai Ajeet Kumar. Studies on the thermal performance of a solar air heater. International Journal of Mechanical Engineering and Technology. 2016; 7(6):518-527.

2. V.V Tyagi, N.L Panwar, N.A.Rahim, Richa Kothari, Review on solar air heating system with and without thermal energy storage system. Renewable and Sustainable Energy reviews, 2012; 16; 2289-2303.

3. Srivastava Ravish and Rai Ajeet Kumar. A review on solar air heater technology. International Journal of Mechanical Engineering and Technology. 2017; 8(7):1122-1131.

4. Akpinar Edru Kavak, et al. Energy and energy analysis of a new flat-plate solar air heater having different obstacles on absorber plates.Applied Energy2010;87:3438-3450.

5. Raj Kumar, Viswamohanpedagopu, Anil Kumar, Robin Thakur \& Anil Pundir, CFD Based Analysis of Heat Transfer and Friction Characteristics of Broken Multiple Rib Roughened Solar Air Heater Duct, International Journal of Mechanical and Production Engineering Research and Development (IJMPERD), Volume 3, Issue 5, November - December 2013, pp. 153-160

6. Chabane Foued, Moummi Noureddine, Benramache Said. Experimental study of heat transfer and thermal performance with longitudinal fins of solar air heater. J Adv Res 2014; 5:183-92.

7. Paisarn Naphon. On the performance and entropy generation of the double-pass solar air heater with longitudinal fins. Renew Energy 2005; 30:1345-57.

8. Omojaro AP, Aldabbagh LBY. Experimental performance of single and double pass solar air heater with fins and steel wire mesh as absorber. Appl Energy 2010; 87:3759-65.

9. Yeh Ho-Ming. Upward-type flat-plate solar air heaters attached with fins and operated by an internal recycling for improved performance. J Taiwan Inst Chem Eng 2012; 43:235-40.

10. Deniz Alta, Emin Bilgili, Ertekin, Yaldiz Osman. Experimental investigation of three different solar air heaters: energy and exergy analyses. Appl Energy 2010; 87:2953-73.

11. Bayraka Fatih, Oztopb Hakan F, Hepbaslic Arif. Energy and exergy analyses of porous ba $\square$ es inserted solar air heaters for 
building applications. Energy Build 2013; 57:338-45.

12. Ho Chii-Dong, Chang Hsuan, Wang Rei-Chi, Lin Chun-Sheng. Performance improvement of a double-pass solar air heater with fins and baffels under recycling operation. Appl Energy 2012; 100:155-63.

13. Mohammadi K, Sabzpooshani M. Comprehensive performance evaluation and parametric studies of single pass solar air heater with fins and ba $\square$ es attached over the absorber plate. Energy 2013; 57:741-50.

14. Ho CD, Yeh HM. The influences of recycle on performance of baffeled double pass flat plate solar air heaters with internal fins attached. Appl Energy 2009; 86:1470-8.

15. Azharul Karima Md, Hawlader MNA. Performance investigation of flat plate, v-corrugated and finned air collectors. Energy 2006; 31:452-70.

16. El-Sebaii AA, Aboul-Enein S, Ramadan MRI, Shalaby SM, Moharram BM. Thermal performance investigation of double passfinned plate solar air heater. Appl Energy 2011; 88:1727-39.

17. Gao Wenfeng, Lin Wenxian, Liu Tao, Xia Chaofeng. Analytical and experimental studies on the thermal performance of crosscorrugated and flat-plate solar air heaters. Appl Energy 2007; 84:425-41.

18. Sanjay Kumar Thakur, Thakur NS, Kumar Anoop, Mittal Vijay. Use of artificial roughness to enhance heat transfer insolar air heaters - a review. J Energy South Afr 2010:21.

19. Singh Yadav Anil, Bhagoria JL. A CFD based thermo-hydraulic performance analysis of an artificially roughened solar air heater having equilateral triangular sectioned rib roughness on the absorber plate. Int J Heat Mass Transf 2014; 70:1016-39.

20. Gupta MK, Kaushik SC. Performance evaluation of solar air heater having expanded metal mesh as artificial roughness on absorber plate. Int J Therm Sci 2009; 48:1007-16.

21. Peng Donggen, Zhang Xiaosong, Dong Hua, Lv Kun. Performance study of a novel solar air collector. Appl Therm Eng 2010;30:2594-601.

22. Momin A-ME, Saini JS, Solanki SC. Heat transfer and friction in solar air heater duct with V-shaped rib roughness on absorber plate. Int J Heat Mass Transf 2002;45:3383-96.

23. Karwa R. Experimental studies of augmented heat transfer and friction in asymmetrically heated rectangular ducts with ribs on the heated wall in transverse, inclined, V-continuous and V-discrete pattern. Int Comm Heat Mass Transf 2003; 30:241-50.

24. Aharwal KR, Gandhi BK, Saini JS. Experimental investigation on heat transfer enhancement due to a gap in an inclined continuous rib arrangement in a rectangular duct of solar air heater. Renew Energy 2008; 33:585-96.

25. Jaurker AR, Saini JS, Gandhi BK. Heat transfer and friction characteristics of rectangular solar air heater duct using ribgrooved artificial roughness. Sol Energy 2006; 80:895-907.

26. Bopche SB, Tandale MS. Experimental investigation on heat transfer and friction characteristics of a turbulator roughened solar air heater duct. Int J Heat Mass Transf 2009; 52:2834-48.

27. Lanjewar AM, Bhagoria JL, Sarviya RM. Thermohydaulic performance of solar air collector using W-shaped artificial roughness. J Environ Res Dev 2012:6.

28. Srivastava Ravishkumar and Rai Ajeet Kumar. Thermal performance investigation of a finned absorber plate solar air heater. International Journal of Mechanical Engineering and Technology. 2017;8(6):622-630. 